\title{
Preventive health services for systemic lupus erythematosus patients: whose job is it?
}

\author{
Paula I Burgos ${ }^{1,2}$ and Graciela S Alarcón*1 \\ See related research by Yazdany et al., http://arthritis-research.com/content/12/3/R84
}

\begin{abstract}
Apropos of the article about preventive health care for patients with systemic lupus erythematosus in this issue of Arthritis Research \& Therapy, we offer some thoughts about how best to delineate the roles of the specialist (rheumatologist) and the generalist in the provision of services to these patients. Even in the best circumstances, these services are now provided at a rate that is less than optimal. We also offer a point about empowering patients to become vigilant about their own care.
\end{abstract}

Over the last few decades, the survival of patients with systemic lupus erythematosus (SLE) has improved dramatically. With these patients living longer, medical care has moved from merely treating the primary condition of the patient to a comprehensive approach that includes the provision of preventive services. How good we are at providing these services and who is responsible for providing them (the specialist as opposed to the generalist) have not been previously addressed. Lupus-related problems that need to be addressed without delay and the limited time allowed per patient visit may curtail the ability of the specialist to provide such services. But poor communication with the specialist may limit the generalist in providing these services, particularly if the latter assumes incorrectly that all health-related issues (preventive services included) are being taken care of by the former. Such assumptions are not uncommon in a less-than-ideal and oftentimes fragmented health care system, such as the one we currently have in the US.

\footnotetext{
*Correspondence: graciela.alarcon@ccc.uab.edu

'Division of Clinical Immunology and Rheumatology, The University of Alabama at Birmingham, 830 Faculty Office Tower, 510th Street South, Birmingham, AL 35294-3408, USA

Full list of author information is available at the end of the article
}

Thus, it is gratifying to note the study by Yazdany and colleagues [1] in this issue of Arthritis Research E Therapy. In this study on the provision of preventive health services to patients with SLE, two categories of preventive services were addressed: cancer prevention and immunizations. The authors studied patients from the Lupus Outcome Study, a longitudinal observational study of more than 1,000 English-speaking patients recruited from academic and non-academic centers and community-based sources in Northern California [2]. Data from the California Health Interview Survey were used for comparison. Only patients for whom a specific service would apply (for example, mammography or colon screening) and the respective population-based data were included in each of the analyses. Patients without health insurance were excluded from the analyses. Of interest, the receipt of preventive services in the lupus patients was comparable to that of the control sample (around 60\% for both cancer prevention and immunization services). Some interesting factors, however, emerged as contributors to lower rates of preventive services, specifically younger age and lower level of education achieved. In addition, having seen a generalist during the preceding year (influenza and pneumococcal immunizations and cervical cancer screening) as well as the total number of physician visits (cancer screening tests) increased the likelihood of receiving preventive services. Finally, patients who had a rheumatologist were more likely to receive influenza immunizations than those who did not have one. In short, even in the best circumstances, preventive services are not being provided adequately: among lupus patients who speak English, are insured, and have a high level of education, about one third did not receive the basic preventive services evaluated. The data from this population cannot be generalized to less fortunate groups of patients with SLE: one can only surmise what the rates would be for the non-English-speaking, poorly educated, uninsured patients with SLE in the US or for patients in developing or underdeveloped areas of the world!

As the authors point out in their discussion, lupus patients are at increased risk of both infections and 
malignancies and thus these preventive services are essential if we are to avoid them (infections) or detect them early (malignancies). So what should the rheumatologist do? Some changes in our practice need to be implemented. Ideally, the changes should be at the system level but that may not be possible except for contained health care systems (for example, HMOs), in which all providers have access to all of a patient's records. Where such access is not possible, reminders in the electronic medical records are a viable option. Unfortunately, however, many patients receive their care outside such systems and thus improvements will require a better level of coordination between generalists and specialists to delineate who is responsible for providing which services and to avoid making baseless assumptions. In addition to improved communication, time for preventive services should be built into these visits (and be considered in the reimbursement process). Efforts should be made to educate the generalist about the importance of these services and to use current guidelines to dispel misconceptions that the patient with lupus may have about the risks associated with immunizations [3]. Finally, only patients who are empowered and become engaged in their care are likely to remind their physicians of the need for preventive services [4]. For instance, patients should be encouraged to keep a calendar of preventive tests and take it with them to their visits. This is particularly important for those patients at higher risk of not obtaining these services: the young and the uneducated or less educated. We and others have shown that many of the less-than-ideal outcomes that patients from minority groups experience (survival and damage accrual) [5-8] relate more to lower socioeconomic status (measured as income, poverty level, or education level attained) than to ethnicity. This study further underscores the importance of socioeconomic status in the course of disease and outcome of patients with SLE and is a reminder that changes at this level may have long-term impact. This study is certainly a call to action. Let us respond to this call!

Abbreviation

SLE, systemic lupus erythematosus.
Competing interests

The authors declare that they have no competing interests.

\section{Acknowledgments}

The work of PIB is supported by the STELLAR (Supporting Training Efforts in Lupus for Latin American Rheumatologists) grant funded by Rheuminations, Inc. (New York, NY, USA).

\section{Author details}

'Division of Clinical Immunology and Rheumatology, The University of Alabama at Birmingham, 830 Faculty Office Tower, 510th Street South, Birmingham, AL 35294-3408, USA. ${ }^{2}$ Department of Clinical Immunology and Rheumatology, School of Medicine, Pontificia Universidad Católica de Chile, Marcoleta 350, Santiago 8330033, Chile.

Published: 17 June 2010

\section{References}

1. Yazdany J, Tonner C, Trupin L, Panopalis P, Gillis JZ, Hersh AO, Julian LJ, Katz PP, Criswell LA, Yelin EH: Provision of preventive health care in systemic lupus erythematosus: data from a large observational cohort study. Arthritis Res Ther 2010, 12:R84.

2. Yelin E, Trupin L, Katz P, Criswell L, Yazdany J, Gillis J, Panopalis P: Work dynamics among persons with systemic lupus erythematosus. Arthritis Rheum 2007, 57:56-63.

3. Yazdany J, Panopalis P, Gillis JZ, Schmajuk G, MacLean CH, Wofsy D, Yelin E; Systemic Lupus Erythematosus Quality Indicators Project Expert Panels: A quality indicator set for systemic lupus erythematosus. Arthritis Rheum 2009, 61:370-377.

4. Karlson EW, Daltroy LH, Lew RA, Wright EA, Partridge AJ, Fossel AH, Roberts WN, Stern SH, Straaton KV, Wacholtz MC, Kavanaugh AF, Grosflam JM, Liang $\mathrm{MH}$ : The relationship of socioeconomic status, race and modifiable risk factors to outcomes in patients with systemic lupus erythematosus. Arthritis Rheum 1997, 40:47-56.

5. Alarcón GS, McGwin G Jr., Bastian HM, Roseman J, Lisse J, Fessler BJ, Friedman AW, Reveille JD: Systemic lupus erythematosus in three ethnic groups. VII [correction of VIII]. Predictors of early mortality in the LUMINA cohort. LUMINA Study Group. Arthritis Rheum 2001, 45:191-202.

6. Durán S, González LA, Alarcón GS: Damage, accelerated atherosclerosis, and mortality in patients with systemic lupus erythematosus: lessons from LUMINA, a multiethnic US cohort. J Clin Rheumatol 2007, 13:350-353.

7. Fernández M, Alarcón GS, Calvo-Alén J, Andrade R, McGwin G Jr., Vilá LM, Reveille JD; LUMINA Study Group: A multiethnic, multicenter cohort of patients with systemic lupus erythematosus (SLE) as a model for the study of ethnic disparities in SLE. Arthritis Rheum 2007, 57:576-584

8. Petri M, Perez-Gutthann S, Longenecker JC, Hochberg M: Morbidity of systemic lupus erythematosus: role of race and socioeconomic status. Am J Med 1991, 91:345-353.

doi:10.1186/ar3040

Cite this article as: Burgos PI, Alarcón GS: Preventive health services for systemic lupus erythematosus patients: whose job is it? Arthritis Research \& Therapy 2010, 12:124. 